$$
\begin{gathered}
\text { DOE/ER/ } 13842 \cdots T 2 \\
{ }_{\text {DOE/ER/13842--T2 }} \\
\text { DE92 } 012228
\end{gathered}
$$

\title{
CYCLOMETALIATED AND CYCLOMETALSILYLATED COMPLEXES OF TRANSITION ELEMENTS AS PHOTOREDOX SENSITIZERS
}

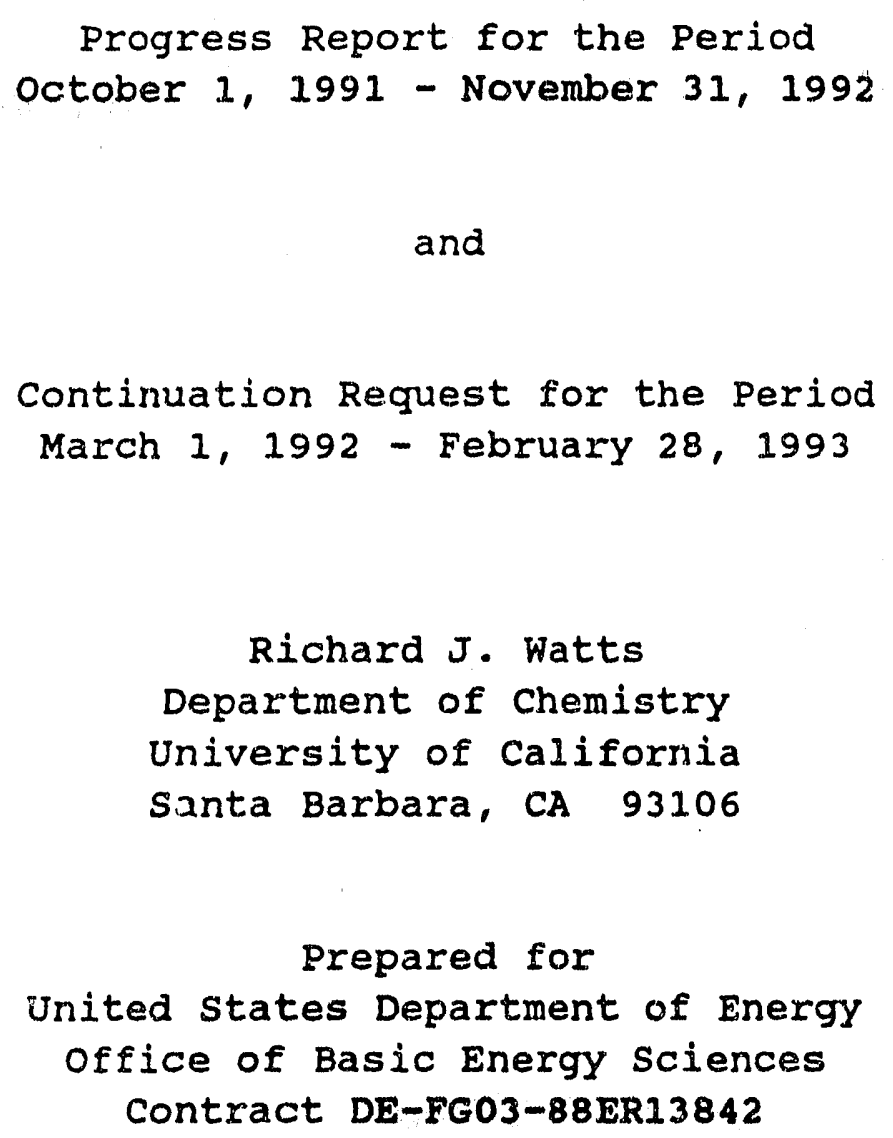

and

Continuation Request for the Period March 1, 1992 - February 28, 1993

Richard J. Watts Department of Chemistry University of California Santa Barbara, CA 93106

Prepared for

United States Department of Energy office of Basic Energy Sciences Contract DE-FG03-88ER13842
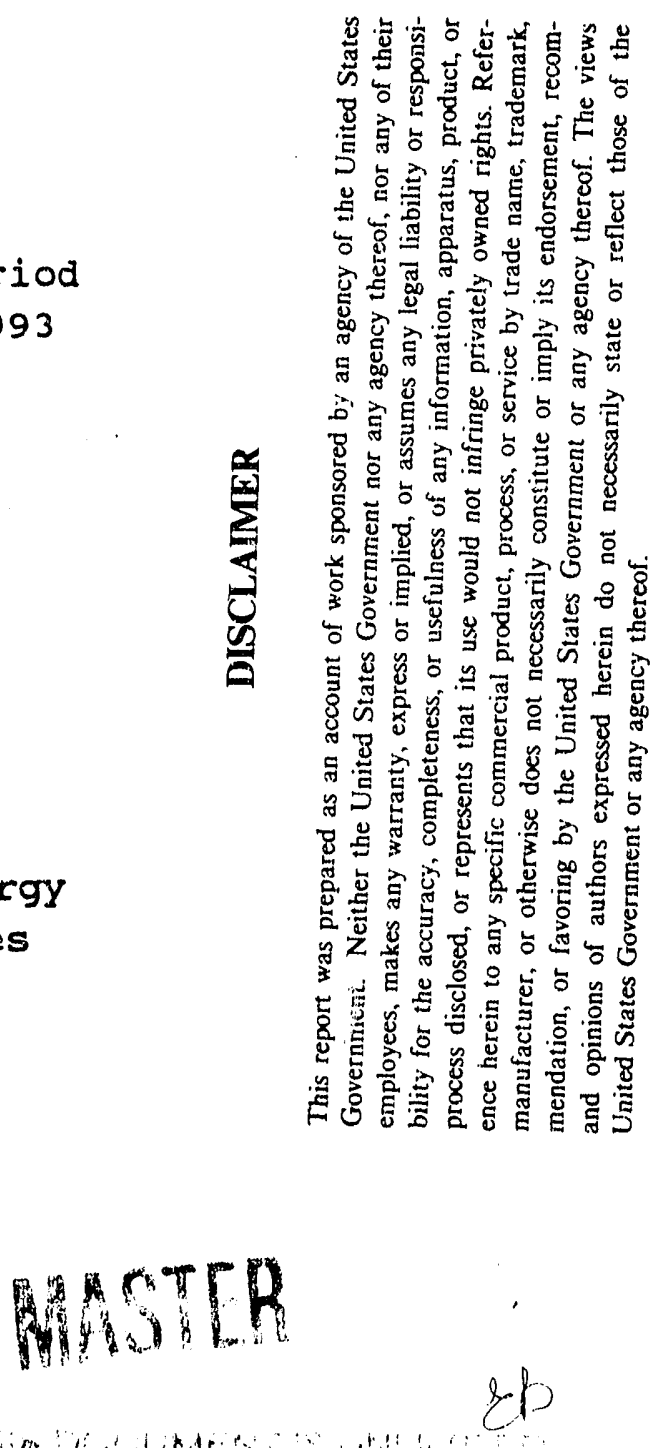


\section{PROGRESS REPORT, 10/1/91-11/30/92}

\section{Ortho-metalated photoreducing Agents.}

An account of a vastly improved synthesis of tris-orthometalated Ir(III) complexes of 2-phenylpyridine and related ligands has been published. 1 The emission energies, excited state lifetimes and ground state oxidation potentials of these species have also been reported, and from these data potentials for the excited states to function as reducing agents can be estimated. These estimates as well as a summary of several potential means for using these and related photocatalysts to carry out demanding chemical reductions and oxidations have also been published. ${ }^{2}$ several projects within this area are being actively researched at this time, including the following: a) production of strong reducing agents by photoreduction of tris-ortho-metalated species; b) precursors for generation of solvated monomeric photocatalysts, and; c) photochemical methanol production from $\mathrm{CO}_{2}$ and $\mathrm{H}_{2} \mathrm{O}$. Brief descriptions of these projects are provided below.

a) Production of strong reducing agents by photoreduction of tris ortho-metalated species. In this project we are attempting to devise systems of reductive quencher/solvent/ ortho-metalated photosensitizer in which visible irradiation will lead to formation of species of the type $\operatorname{Ir}(p p y){ }_{3}{ }^{1-}$ via electron transfer from the quencher to ${ }^{\star} \operatorname{Ir}(p p y)_{3}$ or a related complex. Reduced complexes of the type $\operatorname{Ir}(\mathrm{ppy})_{3} 3^{1-}$ should be even stronger reducing agents than ${ }^{*} \operatorname{Ir}(p p y)_{3} 2-5$, and are not subject to the kinetic limitations inherent in spontaneous radiative and non-radiative decays of excited state reducing agents. The solubility properties of the photosensitizers requires use of solvents such as acetonitrile or toluene for this work, and relatively few mild organic reducing agents are suited to perform the reduction of ${ }^{*} \operatorname{Ir}(\mathrm{ppy})_{3}$. Potential quenchers must be soluble in compatable solvents, provide sufficient reducing power to transfer an electron to

${ }^{*} \operatorname{Ir}(\mathrm{ppy})_{3}$ and lack low energy excited states which might lead to quenching via energy transfer rather than electron transfer. We are presently using stern-Volmer methods to characterize quenching of ${ }^{*} \operatorname{Ir}(\mathrm{ppy})_{3}$ by several tertiary aromatic amines which appear to be suited to the task. This study will be extended to related tris ortho-metalated complexes as our knowledge of optimal quenchers to perform the reduction is refined. The value of $\xi^{\circ}$ for the couple 
$\operatorname{Ir}(p p y)_{3} / \operatorname{Ir}(p p y)_{3}{ }^{1-}$ is known to be about $-2.0 \mathrm{~V}$ vs SCE, and electron donating substituents on ppy will shift this more negative by several hundred millivolts. Once $\operatorname{Ir}_{\text {(ppy) }}{ }^{1-}$ has been well-characterized in these reversible systems, we will seek to devise irreversible systems in which $\operatorname{Ir}(p p y)^{1-}$ is produced and then studied for its ability to drive difficult chemical reductions of carbon-containing substrates such as $\mathrm{CO}_{2} \cdot$

b) Precursors for generation of solvated monomeric photocatalysts. In this project we are preparing and studying dichloro-bridged dimers of $\operatorname{Ir}$ (III) and $\mathrm{Rh}$ (III) as precursors to photoelectrochemical catalysts which might be attached to electrode surfaces and/or used to coordinate substrates prior of photochemical electron transfer reactions. The prototype precursor for this work is $\left[\operatorname{Ir}(\mathrm{ppy})_{2} \mathrm{Cl}_{2}\right.$, which, like the tris ortho-metalated species, can be modified substantially with electron donating and/or electron withdrawing substituents. The dichloro-bridged dimers can then be converted to solvated monomers by reaction with an organic silver salt. The range of ligand substituents which have been successfully used in this project is quite extensive, and it has become clear that many of the substituted ppy ligands which do not form tris ortho-metalated species will react readily to form dichloro-bridged dimers. We are presently in the process of characterizing the photoproperties of a wide range of these species, several of which are being employed in the following project.

c) Photochemical methanol production from $\mathrm{CO}_{2}$ and $\mathrm{H}_{2} \mathrm{O}$. A variety of photochemical systems have been devised in which $\mathrm{CO}_{2}$ and $\mathrm{H}_{2} \mathrm{O}$ are caused to react to form products such as $\mathrm{CO}$ or formate ion. We are presently exploring the possibility of selective photochemical reduction of $\mathrm{CO}_{2}$ to methanol without formation of these two-electron reduction products. Although relatively little is known of methods by which this type of selective reduction might be achieved, Ogura ${ }^{6-10}$ has performed extensive studies of electrochemical and photoelectrochemical processes in which this type of selective reduc-tion of $\mathrm{CO}_{2}$ to $\mathrm{CH}_{3} \mathrm{OH}$ has been reported. The primary components of Ogura's methanol production systems consist of a Pt electrode which is coated with Everitt's salt ( $\left.\mathrm{K}_{2} \mathrm{Fe}\left[\mathrm{Fe}(\mathrm{CN})_{6}\right]\right)$ and $\mathrm{a}_{2}$ saturated solution containing a transition metal catalyst with a coordination site occupied by a labile solvent ligand $\left(\mathrm{Fe}(\mathrm{CN}){ }_{5} \mathrm{H}_{2} \mathrm{O}\right.$ for example). The solution catalyst is thought to first bind solvent methanol and then $\mathrm{CO}_{2}$, and 
this is followed by a series of reduction steps in which water is formed and protons react with the complex to form two equivalents of methanol with re-formation of the solution catalyst. Ogura reports that only the Everitt salt derivatized electrode is selective in forming methanol, suggesting that binding of the solution catalyst to the electrode at some intermediate stages might be involved in the selectivity of the system.

In this project we are attempting to combine the function of the Everitt salt and the solution catalyst in one ortho-metalated species. The solvated species is formed by reacting one of the dichloro-bridged dimers described above with an organic silver salt to remove the bridging chlorides as insoluble $\mathrm{AgCl}$. We are attrmpting to study binding of methanol and carbon dioxide by the resulting solvated species in several different solvent systems. It is clear from Ogura's work that binding of methanol and $\mathrm{CO}_{2}$ by the solution catalyst is a key step in the formation of more methanol via $\mathrm{CO}_{2}$ reduction. In addition to these studies of methanol and carbon dioxide binding, we have begun to develop procedures for coating pt electrodes with the solvated metal complexes via solvent evaooration. At the present time, we have been able to prepare the acetonitrile derivative of $\left[\mathrm{Ir}(\mathrm{ppy})_{2} \mathrm{Cl}_{2}\right.$ by reaction of the dimer with silver triflate and to deposit the resulting triflate salt on pt electrodes. The resulting film is insoluble in aqueous methanol solutions which will be used to study the possibility of photoelectrochemical methanol production.

\section{Photoproperties of Metal-silicon Chelated Complexes.}

Our work in this area has been concentrated upon the preparation and characterization of Ir(III), $R h$ (III) and Pt(II) complexes of ligands based upon 8-silylquinoline. We designed and prepared this type of ligand (Fig 1) in order to stabilize metal-silicon bonds via chelation, while also providing good electron accepting (quinoline) and electrondonating $\left(S i R_{2}\right)$ sites to promote optical charge-transfer transitions. Metal silyls have been extensively studied for their thermal catalytic properties (polymerization of monosilanes to polysilanes, for example), and chelate-assisted hydrosilylation $11-18$ has been used as a method to stabilize metal-silicon bonds with phosphinosilyl ligands. However, this work is providing the first account of photoproperties

$$
-6-
$$


of chelated metal silyl complexes.<smiles>[R2][SiH]([R1])c1cccc2cccnc12</smiles>

Figurel. Structure of (8-quinoline)diorganosilane Ligand precursors $\left(R_{1}, R_{2}=\right.$ methyl, phenyl, $\left.H\right)$.

our initial efforts in this area has led to the development of a synthetic route to tris chelated complexes of the type illustrated in Figure 2. These complexes, which have

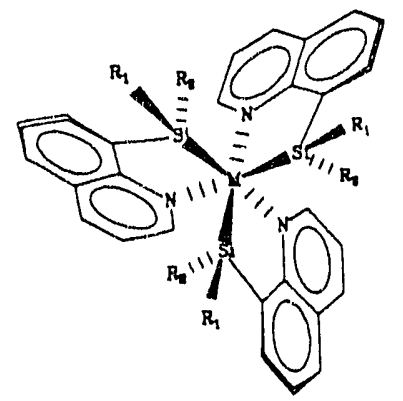

Figur, 2. Structural Representation of fac-tris [8-(Diorgnosilyl)quinolyl] Complexes of $\operatorname{Ir}\left(\right.$ III) or $R h(I I I)\left(R_{1}, R_{2}=\right.$ methyl, phenyl or $\mathrm{H}$ ).

been characterized with either $R h$ (III) or $\operatorname{Ir}$ (III) as the central metal, are the first reported examples of tris (N,Si-) chelated species. Both complexes emit from excited states which are believed to arise from charge-transfer of a metalsilicon bonding electron to a $\mathrm{pi}^{*}$ quinoline orbital. similar types of excited states have been discussed for $\operatorname{Re}(I)-S n$ and $\mathrm{Re}(I)-\mathrm{Ge}$ bonded species.19-22 our initial work in this area was described 23 at the 9 th ISPPCC in Fribourg, switzerland, and has been accepted for publication. 24 A second manuscript describing $X-r a y$ and NMR structural studies of these complexes will soon be submitted for publication. During the next year, we will extend our spectroscopic studies of these species to more fully characterize their excited state structures, and will begin the first studies designed to characterize their interactions with oxidative quenchers. 
3. Detailed Electronic structure and Energy Transfer in ortho-metalated complexes.

Work in this area has resulted in two recent publications 25,26 in which excited state dipole moments and dual emissions in mixed ortho-metalate/chelate complexes (ppy and bpy, for example) have been characterized. The published dual emission work was limited to a study of emissions at 77 $K$, and more recently we have completed an extensive study of dual emission in $\operatorname{Ir}(p p y)_{2}(b p y)^{+}$and in $\operatorname{Ir}(p p y)_{2}\left(b p y-d_{8}\right)^{+}$as a function of temperature $(80 \mathrm{~K}-300 \mathrm{~K})$ in several different solvents. Dramatic changes in the emission spectra occurs over this range, as illustrated in Figure $3 a, b$ on the following page. A broad emission associated with MLCT to bpy progressively red-shifts between $80 \mathrm{~K}$ and $300 \mathrm{~K}$, with a dramatic red-shift over a small temperature range associated with the glass/fluid transition in propanol (160 - $170 \mathrm{~K}$ ). A higher energy somewhat structured emission, associated with MLCT to ppy, shifts relatively little but intensifies relative to the MLCT state of bpy in the glass/fiuid transition region. This complex behavior is believed to arise from a combination of relaxation to the ground state and interligand electron hopping moderated by solvent dynamics. The dynamic behavior of electron hopping in the glass/fluid transition region is of particular interest since static dielectric relaxation of the solvent becomes a relevant factor in this region. 27-33 We are presently developing a model to interpret the different temperature dependencies of the two emissions which emphasizes that the excited state dipoles of the two excited states requires rather different solvent optical and static dielectric relaxation.

The time-resolved emission of $\operatorname{Ir}(p p y)_{2}$ (bpy) $^{+}$is displayed in Figure $4 a, b$, which illustrates that the MLCT to ppy excited state retains a much longer lifetime than the MLCT to bpy state as the temperature is increased, particularly in the glass/fluid transition region. A detailed ananlysis of the decay kinetics over the full $80-300 \mathrm{~K}$ temperature range has been completed for both $\operatorname{Ir}(\mathrm{ppy})_{2}$ (bpy) $^{+}$and for $\operatorname{Ir}(p p y)_{2}\left(b p y-d_{8}\right)^{+}$, and this has been compared to similar data for $\operatorname{Ir}(p p y)_{3}$. A manuscript describing this analysis and the resulting estimates for rates of electron hopping is presently in preparation. 
a)

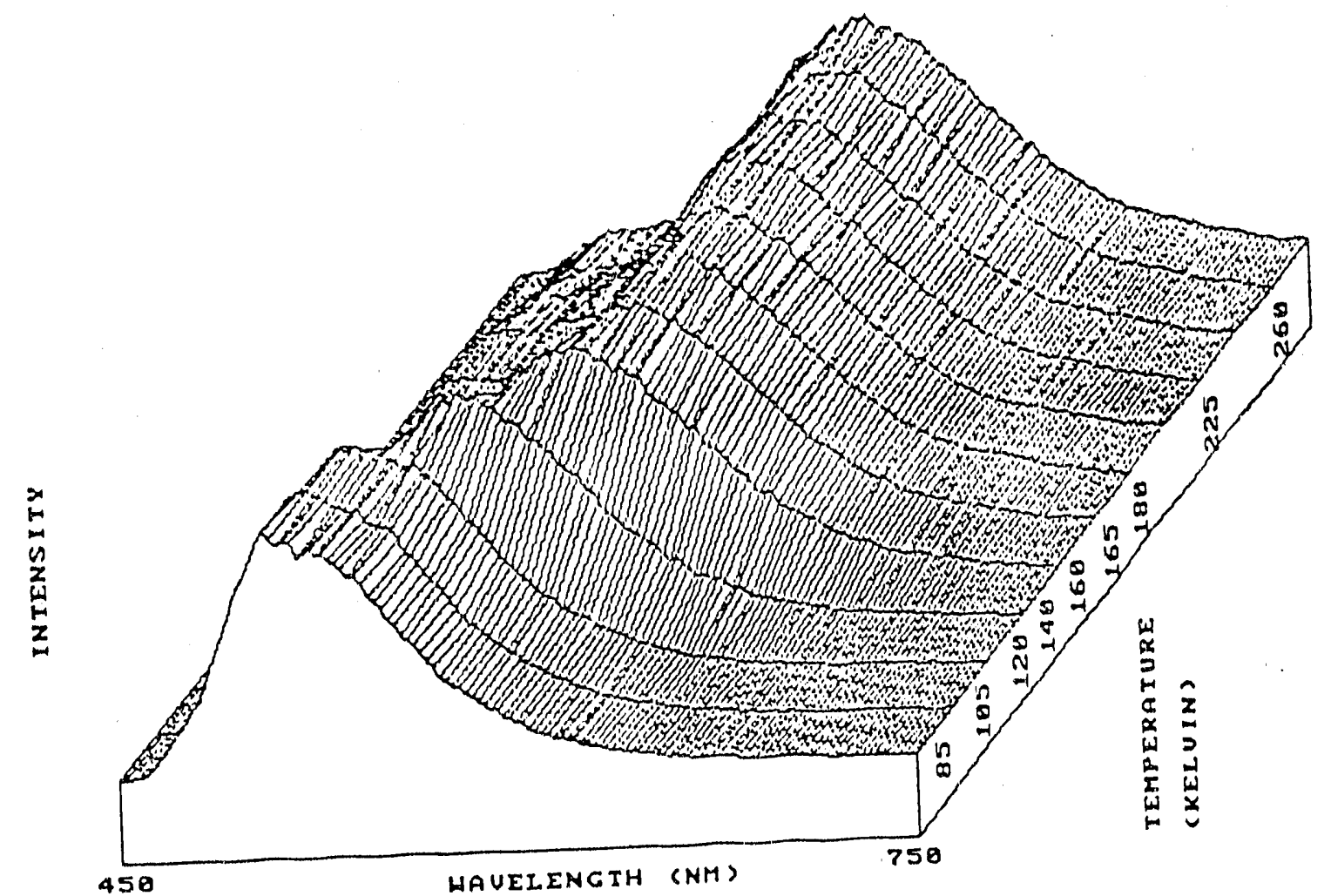

b)

$\frac{x}{2}$

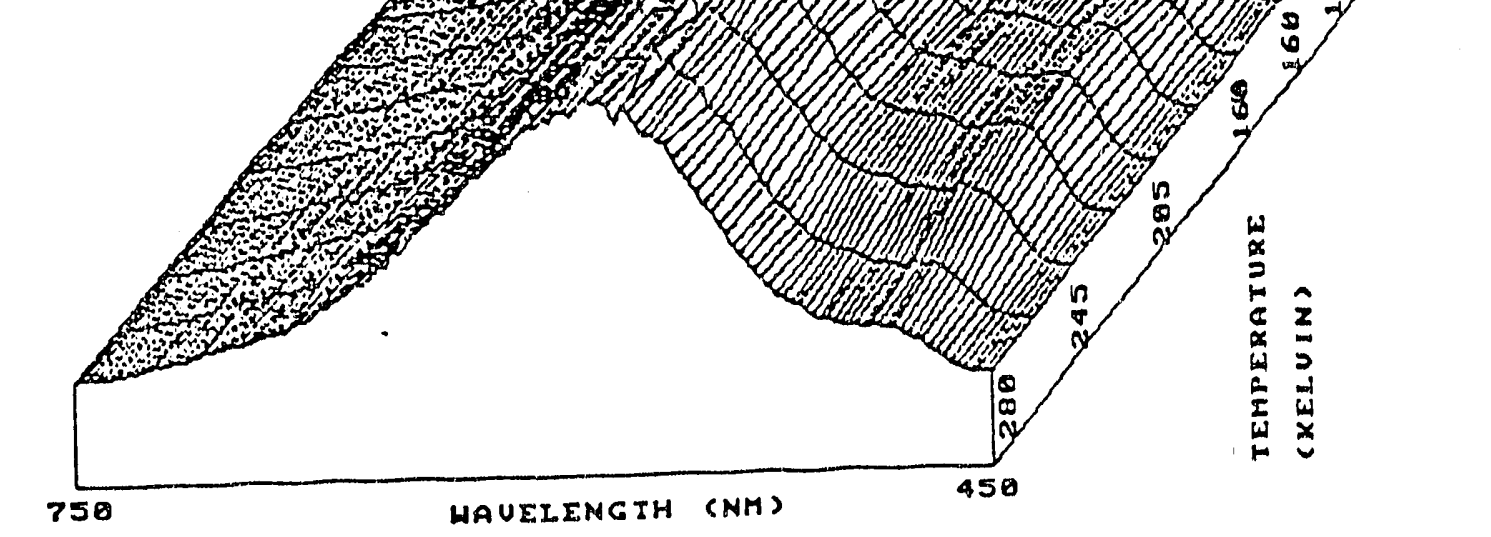

Figure 3. Emission Spectra of $\operatorname{Ir}\left(\right.$ ppy) ${ }_{2}$ (bpy $^{1+}$ as a Function of Temperature In n-Propanol. Two Different Perspectives Are Shown in a) and b). The Spectrum at each Temperature Has Been Normalized to Unity at the Maximum. 
a)
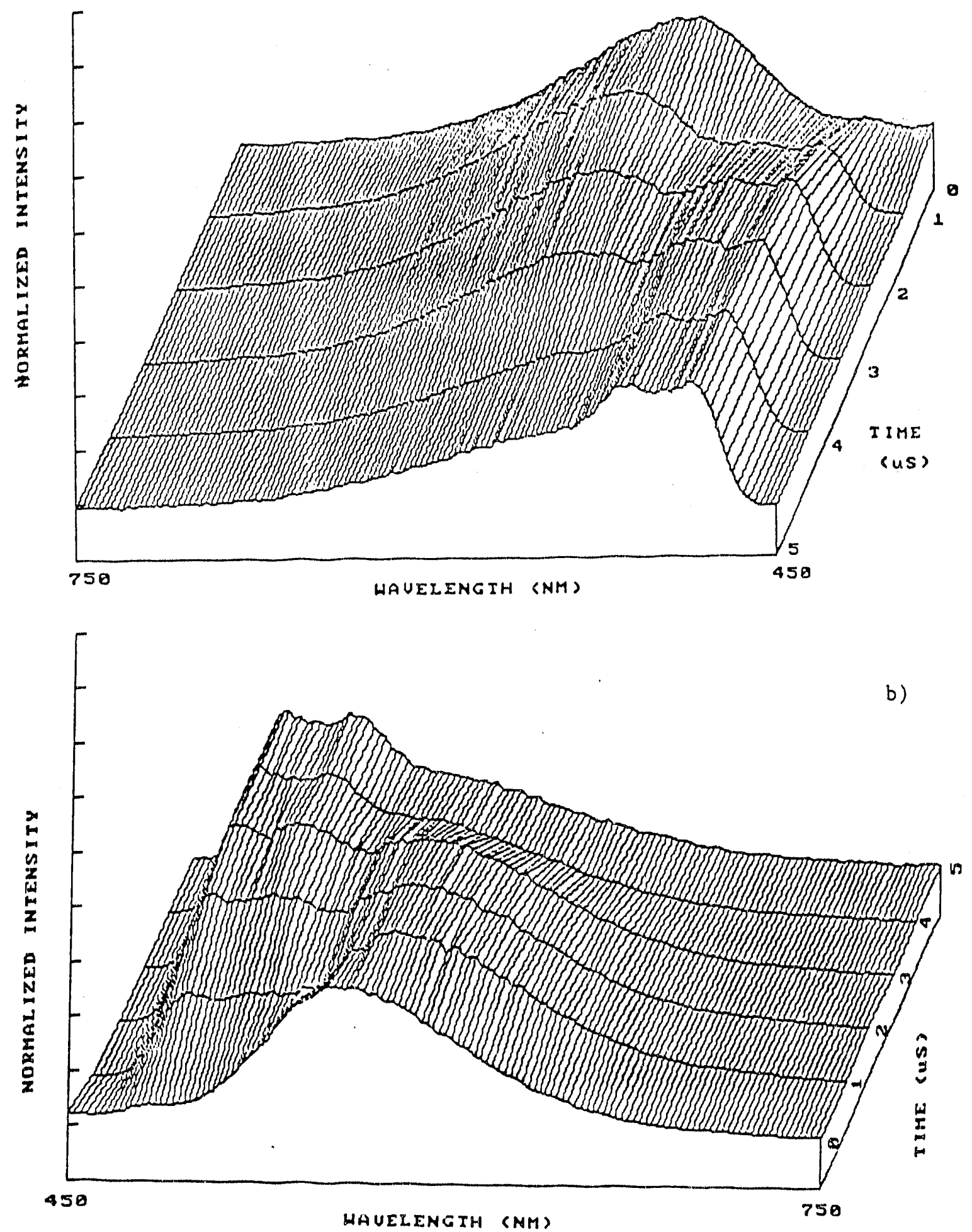

Figure 4. Time-Resolved Emission Spectra of $\operatorname{Ir}\left(\right.$ ppy) ${ }_{2}$ (bpy) ${ }^{1+}$ in Propanol at $165 \mathrm{~K}$. Two Different Perspectives Are Shown in a) and b). The Spectrum at each Time Has Been Normalized to Unity at the Maximum. 


\section{Literature cited.}

1. Dedeian, K.; Djurovich, P.I.; Garces, F.0.; Carlson, G.; Watts, R.J. Inorg. Chem. 1991, 30, 1685.

2. Watts, R.J. Comments Inorg. Chem. 1991, 11, 303.

3. King, K.A.; Finlayson, M.F.; Spellane, P.J.; Watts, R.J. Sci. Papers I.P.C.R. 1984, 78, 97.

4. King, K.A.; Spellane, P.J.; Watts, R.J. J. Am. Chem. Soc. $1985,107,1431$.

5. Ohsawa, Y.; Sprouse, S.; King, K.A.; DeArmond, M.K.; Hanck, K.W.; Watts, R.J. J. Phys. Chem. 1987, 91, 1047.

6. Ogura, K. J. Electrochem. Soc. 1987, 134, 2749.

7. Ogura, K.; Fujita, M. J. Mol. Catal. 1987, 11, 303.

8. Ogura, K.; Yoshida, I. Electrochim. Acta. 1987, 32, 1191.

9. Ogura, K.; Migita, C.T.; Imura, H. J. Electrochem. Soc. $1990,137,1730$.

10. Ogura, K.; Migita, C.T.; Nagaoka, T. J. Mol. Catal. 1989, 56,276 .

11. R. D. Holmes-smith, S. R. Stobart, T. S. Cameron, and

K. Jochem, J. Chem. Soc. Chem. Commun. 1981, 937 .

12. M. J. Auburn, R. D. Holmes-smith, S. R. Stobart, M. J. Zaworotko, E. Brennan and T. S. Cameron, J. Chem. Soc.

Chem. Commun. 1983, 1523.

13. M. J. Auburn, R. D. Holmes-Smith and S. R. Stobart, $J$. Am. Chem. Soc. 1984, 106, 1314.

14. M. J. Aubuxn and S. R. Stobart, J. chem. Soc. Chem. Commun. 1984, 284.

15. M. J. Auburn and S. R. Stobart, Inorg. Chem. 1985, 24, 318 .

16. M. J. Auburn, S. L. Grundy, S. R. Stobart and M. J.

Zaworotko, J. Am. Chem. 80c. 1985, 107, 266.

17. F. L. JosI in and S. R. Stobart, J. Chem. soc. Chem.

Commun. 1989, 504 .

18. S.L. Grundy, R.D. Holmes-Smith, S.R. Stobart and M.A.

Williams, Inorg. Chem. 1991, 30, 3333.

19. J. C. Luong, R. A. Faltynek and M. S. Wright'un, J. Am. Chem. Soc. 1979, 101, 1597 .

20. J. C. Luong, R. A. Faltynek and M. S. Wrighton, J. Am. Chem. Soc. 1980, 102, 7892 .

21. R. R. Andrea, W. G. J. de Lange, D. J. Stufkens and A. Oskam, Inorg. Chim. Acta 1988, 149, 77 .

22. R. R. Andrea, W. G. J. de Lange, D. J. Stufkens and A. Oskam, Inorg. Chem. 1989, 28, 318 . 
23. P.I. Djurovich, A. Safir, N. Keder and R.J. Watts, Ninth International symposium on the Photochemistry and Photophysics of Coordination compounds Fribourg, Switzerland, 1991, Abstract 0-17, p26.

24. P.I. Djurovich, A. Safir, N. Keder and R.J. Watts, coord. Chem. Rev. in press.

25. A.P. Wilde and R.J. Watts, J. Phys. Chem. 1991, 95, 622. 26. A.P. Wilde, K.A. King and R.J. Watts, J. Phys. Chem. 1991，95, 629.

27. B.S. Brunschwig, S. Ehrenson and N. Sutin, J. Phys. Chem. 1987, 91, 4714 .

28. M. Kozik, N. Sutin and J.R. Winkler, Coord. Chem. Rev. $1990,97,23$.

29. N. Kitamura, H.-B. Kim, Y. Kawanishi, R. Obata and S. Tazuke, J. Phys. Chem. 1986, 90, 1488.

30. J.D. Simon, ACC. Chem. Res. 1988, $21,128$.

31. P.F. Barbara and W. Jarzeba, ACC. Chem. Res. 1988, 21 , 195.

32. M. Maroncelli, J. Macinnis and G.R. Fleming, science $1989,243,1674$.

33. G. van der iwan and J.T. Hynes, J. Phys. Chem. 1985, 89, 4181. 


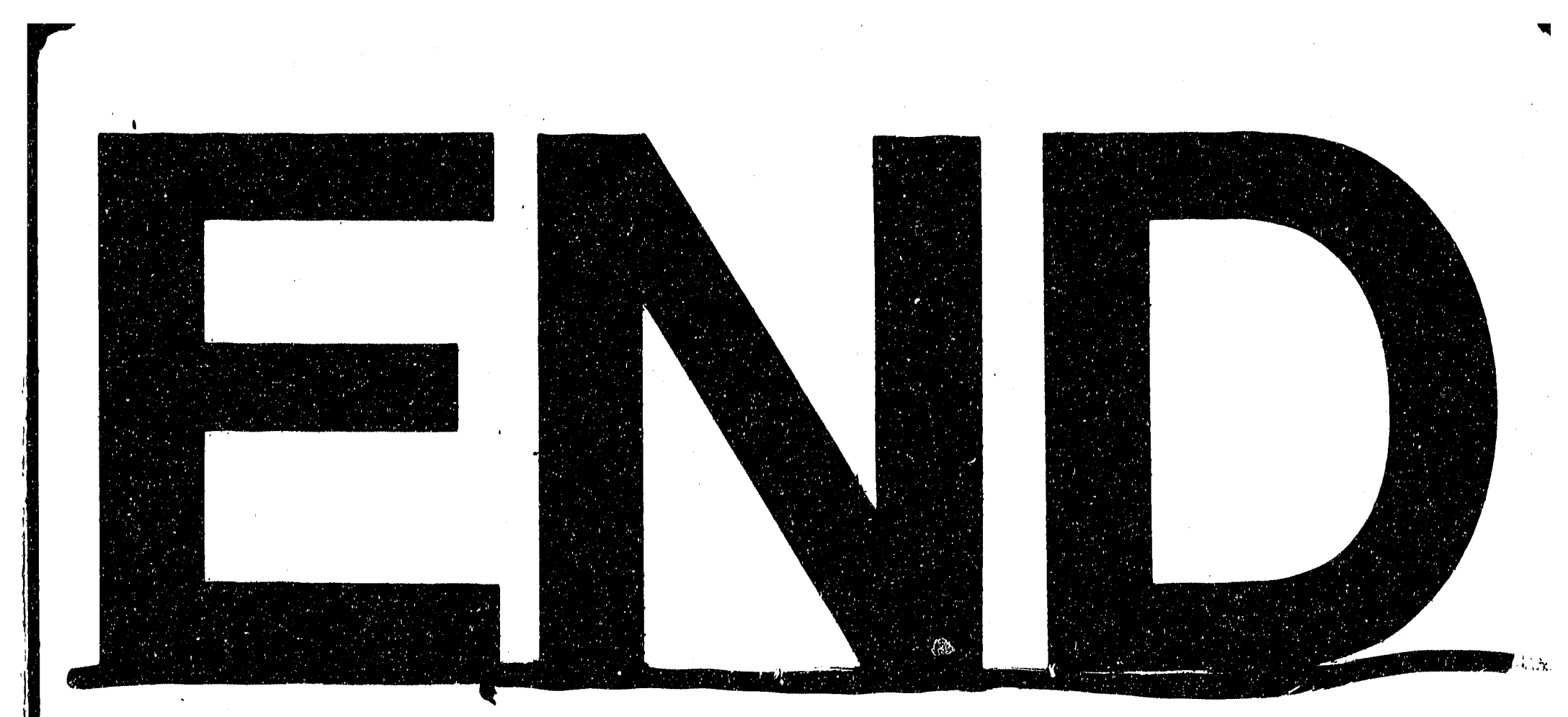




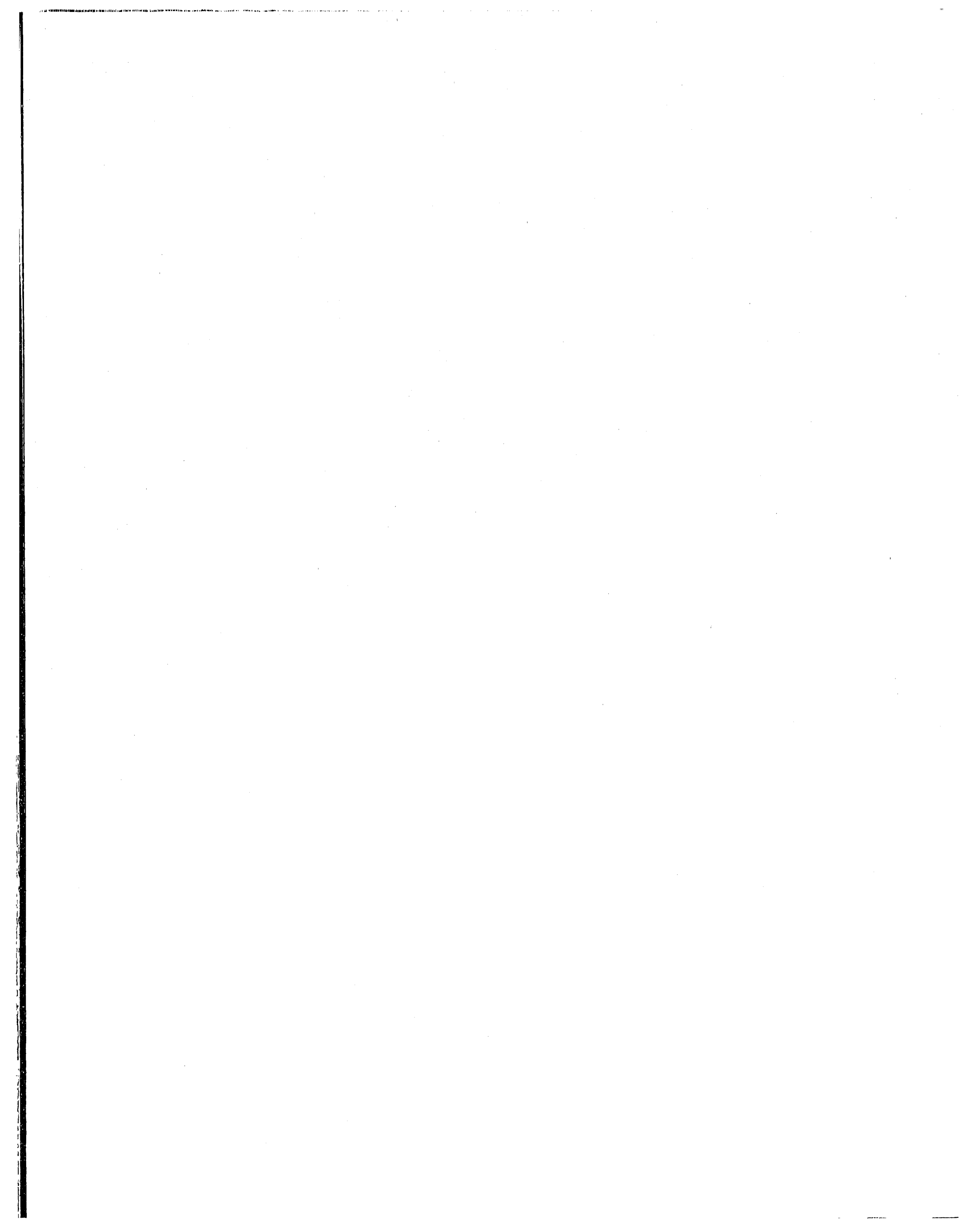

